\title{
Engineered D2R Variants Reveal the Balanced and Biased Contributions of G-Protein and $\beta$-Arrestin to Dopamine- Dependent Functions
}

\author{
Samuel J Rose', Thomas F Pack', Sean M Peterson', Kaitlin Payne', Emiliana Borrelli ${ }^{2}$ and Marc G Caron ${ }^{*, 1,3}$ \\ 'Department of Cell Biology, Duke University Medical Center, Durham, NC, USA; ${ }^{2}$ Department of Microbiology and Molecular Genetics, University \\ of California, Irvine, Irvine, CA, USA; ${ }^{3}$ Department of Medicine and Neurobiology, Duke University Medical Center, Durham, NC, USA
}

\begin{abstract}
The dopamine D2 receptor (D2R), like many G-protein-coupled receptors, signals through G-protein- and $\beta$-arrestin-dependent pathways. Preferential activation of one of these pathways is termed functional selectivity or biased signaling and is a promising therapeutic strategy. Though biased signaling through D2Rs has been demonstrated, acquiring the mechanistic details of biased D2R/G-protein and $\mathrm{D} 2 \mathrm{R} / \beta$-arrestin signaling in vivo has been challenging because of the lack of techniques that specifically target these interactions in discrete cell populations. To address this question, we employed a cell type-specific viral expression approach to restore D2R variants that preferentially engage either G-protein or $\beta$-arrestin signaling in 'indirect pathway' medium spiny neurons (iMSNs), because of their central role in dopamine circuitry. We found that the effect of haloperidol antagonism on D2R metabolic signaling events is largely mediated by acute blockade of D2R/G-protein signaling. We show that a D2R-driven behavior, nestlet shredding, is similarly driven by D2R/G-protein signaling. On the other hand, D2R-driven locomotion and rearing require coordinated D2R/G-protein and D2R/ $\beta$-arrestin signaling. The acute locomotor response to amphetamine and cocaine similarly depend on both G-protein and $\beta$-arrestin D2R signaling. Surprisingly, another psychotropic drug, phencyclidine, displayed a selective D2R/ $\beta$-arrestin potentiation of locomotion. These findings highlight how D2R mostly relies upon balanced G-protein and $\beta$-arrestin signaling in iMSNs. However, the response to haloperidol and phencyclidine indicates that normal D2R signaling homeostasis can be dramatically altered, indicating that targeting a specific D2R signal transduction pathway could allow for more precise modulation of dopamine circuit function.

Neuropsychopharmacology (2018) 43, II64-I 173; doi:I0.1038/npp.2017.254; published online 20 December 2017
\end{abstract}

\section{INTRODUCTION}

Dysfunction of dopamine D2 receptor (D2R) signaling is implicated in many neurological and psychiatric disorders including schizophrenia, attention deficit hyperactivity disorder, and Parkinson's disease. Compounds that modulate dopamine levels or target D2R directly have been intensely pursued for several decades (Seeman et al, 1976; Carlsson, 1978; Weinberger, 1987; Kane et al, 1988) with many successfully clinical treatments in wide use. It is now well recognized that G-protein-coupled receptors (GPCRs), which includes the D2R, signal through G-protein-dependent and G-protein-independent mechanisms. Goi/omediated D2R signaling inhibits adenylyl cyclase and cyclic adenosine monophosphate (cAMP) production (Kebabian and Calne, 1979; Nishi et al, 1997). G-protein-independent D2R signaling, however, is initiated by GPCR-kinase (GRK)-

* Correspondence: Professor MG Caron, Department of Cell Biology, Duke University Medical Center, 487 CARL Building, Research Drive, Durham NC 277I0, USA, Tel: + 919684 5433, Fax: + I 91968 | 864I, E-mail: marc.caron@duke.edu

Received 24 August 2017; revised 26 September 2017; accepted 16 October 2017; accepted article preview online 25 October 2017 dependent phosphorylation of $\mathrm{D} 2 \mathrm{R}$, and the subsequent interaction of $\mathrm{D} 2 \mathrm{R}$ with the multifunctional adaptor protein $\beta$-arrestin2. Along with desensitizing G-protein-dependent signaling, the $\mathrm{D} 2 \mathrm{R} / \beta$-arrestin2 interaction initiates signaling in its own right (Beaulieu et al, 2005; Urs et al, 2012). In certain instances, a single ligand for a GPCR, including some examples for D2R, can serve as an agonist to one of these pathways, but not the other. This selective activation of a given pathway is termed functional selectivity or biased signaling and represents a promising pharmacotherapeutic strategy (Bohn et al, 2000; Allen et al, 2011; Whalen et al, 2011). Indeed, functionally selective D2R ligands would fulfill an unmet need because of the relatively poor efficacy and broad side-effect profile of existing D2R ligands (Lieberman et al, 2005).

Harnessing the therapeutic potential of functionally selective D2R signaling requires a better understanding of $\mathrm{D} 2 \mathrm{R}$ signaling bias in relevant neural cell types, where the biased signaling profile of a receptor is determined by the expression level of GRKs, arrestins, and likely many other factors (Urs et al, 2016). Complicating this effort, D2Rs are expressed in many brain regions, including cortex, hypothalamus, amygdala, midbrain, and striatum (Weiner et al, 
1991). In the striatum alone, D2Rs are expressed by several cell types including cholinergic interneurons (Kharkwal et al, 2016a), $\gamma$-aminobutyric acid (GABA)-ergic interneurons (Centonze et al, 2003), projections from midbrain dopaminergic neurons (Bello et al, 2011), as well as on medium spiny neurons (also known as spiny projection neurons) that project to the so-called 'indirect pathway' (iMSNs) in the classical go-no-go basal ganglia model (Alexander et al, 1986; Gerfen et al, 1990). Though D2Rs play an important role for each of these cell types, recent studies using cell type-specific knockouts illustrate the necessity of D2Rs expressed by iMSNs (iMSN-D2Rs) for many behavioral and physiological functions (Dobbs et al, 2016; Kharkwal et al, 2016b; Lemos et al, 2016). iMSN-D2R knockout mice mimic whole-body $\mathrm{D} 2 \mathrm{R}$ knockout mice in that they exhibit deficits in locomotion, skilled movements, and the acute response to cocaine (Baik et al, 1995). Therefore, we sought to define the contributions of D2R/G-protein and D2R/ $\beta$-arrestin signaling in iMSNs with respect to behavior, antipsychotic, and psychotropic responses in mice.

To investigate functionally selective signaling in iMSND2Rs, we combined cell type-specific knockout with our recently characterized biased D2R variants (Peterson et al, 2015) for a viral reconstitution approach. We first used a Cre-lox approach to delete D2Rs in iMSNs. Then we reexpressed D2R variants engineered to preferentially engage either D2R/G-protein (mostly G $\alpha \mathrm{i} / \mathrm{o}$ ) or $\mathrm{D} 2 \mathrm{R} / \beta$-arrestin (mostly $\beta$-arrestin2) signaling. This viral reconstitution approach allows for cell type-specific manipulation, an advantage over most pharmacological approaches. Furthermore, this approach targets only the interaction between G-protein and $\beta$-arrestin with D2Rs, an advantage over gene knockout approaches that disrupt the signaling of other GPCRs. Furthermore, with side-by-side investigation of both biased D2R variants, this approach allows for an impartial comparison between $\mathrm{D} 2 \mathrm{R} / \mathrm{G}$-protein and $\mathrm{D} 2 \mathrm{R} / \beta$-arrestin signaling with regard to their functional effects. Through this approach, we evaluate how $\mathrm{D} 2 \mathrm{R}$ undergoes alterations to the balance between G-protein and $\beta$-arrestin signaling under various physiological states.

\section{MATERIALS AND METHODS}

\section{Mouse Lines}

All animal studies were conducted in accordance with the Duke University Institutional Animal Care and Use Committee and in accordance with the NIH guidelines. Drd2 flox/flox:: Adora2A-Cre ${ }^{+/-}\left(\mathrm{iMSN}-\mathrm{D} 2{ }^{\mathrm{KO}}\right)$ and Drd2 flox/flox littermates (Cre-controls), on a C57BL/6J background, were generated as previously described (Urs et al, 2016). Male and female adult mice (2-6 months of age) were used for all studies. Animals were housed in a $12 \mathrm{~h}$ light/dark cycle in temperature- and humidity-controlled environment with food and water access ad libitum.

\section{Viral Vectors and Stereotaxic Surgeries}

D2R expression vectors were similar to those in Peterson et al (2015), with slight modifications. Briefly, a gene block (Integrated DNA Technologies, Coralville, IA) was designed containing mCerulean-P2A-HA sequences flanked by $5^{\prime}$
KpnI and $3^{\prime}$ BamHI sites and was cloned into the pcDNA3.1 vector. Then, the WT and mutant D2Rs were PCR amplified with primers adding $5^{\prime} \mathrm{BamHI}$ and $3^{\prime}$ EcoRI sites and then ligated into the above vector. This construct was then cut and ligated in the reverse orientation using the NheI and AscI sites in a pAAV-DIO vector.

Constructs were packaged into adeno-associated virus (AAV) pseudotype 10 using the triple-transfection technique, as previously described (Xiao et al, 1998). Titers of each virus were determined to be between $1 \times 10^{12}$ and $1 \times 10^{13}$ vector genomes/ml using qPCR.

With mice anesthetized under $2 \%$ isoflurane, viruses were delivered at $\mathrm{AP}=+1.1 \mathrm{~mm}, \mathrm{ML}= \pm 1.7 \mathrm{~mm}, \mathrm{DV}=-2.9 \mathrm{~mm}$ (dorsal striatum), and $-4.0 \mathrm{~mm}$ (ventral striatum). To each site, $0.75 \mu \mathrm{l}$ was delivered bilaterally. Mice were allowed to recover for 2 weeks before any experimentation.

\section{Drugs}

D-Amphetamine, cocaine $\mathrm{HCl}$, and phencyclidine $\mathrm{HCl}$ were obtained from Sigma-Aldrich (St Louis, MO), dissolved in sterile $0.9 \%$ saline, and delivered i.p. at $10 \mathrm{ml} / \mathrm{kg}$ bodyweight. Haloperidol (Sigma-Aldrich) was dissolved in minimal glacial acetic acid and brought to volume in saline. $\mathrm{pH}$ was adjusted to 6.0 with $\mathrm{NaOH}$ and was delivered i.p. at $5 \mathrm{ml} / \mathrm{kg}$.

\section{Histology}

Histological procedures are detailed in the Supplementary Materials and Methods. To estimate the volume of striatum with viral expression, every sixth brain section was imaged at $\times 12$ with an AxioZoom v16 microscope equipped with Zen image acquisition software (Zeiss, Oberkochen, Germany). Using NIH ImageJ software (Bethesda, MD), a blinded observer traced the striatum according to a mouse brain atlas, along with the portion of striatum that had mCerulean+ expression. Percentage volume with expression was estimated by dividing the mCerulean + area, in $\mathrm{mm}^{2}$, by total striatal area, in $\mathrm{mm}^{2}$. The intensity of $\mathrm{HA}+$ immunostaining was measured using the ImageJ mean gray value measure, where gray value was assessed following black and white conversion of the image and background subtraction.

For signaling experiments, $1: 500$ dilutions of Rabbit antic-fos (Santa Cruz Biotechnology, Santa Cruz, CA), Rabbit anti-phospho-H3 (Ser10) (Cell Signaling Technology), Rabbit anti-Jun (Cell Signaling Technology), Rabbit anti-egr1 (Santa Cruz Biotechnology), and Rabbit anti-phospho S6 (Ser235/236) (Cell Signaling Technology) were used to label cellular markers. The $\times 125$ double-labeled images were taken on an AxioZoom v16 microscope. Cell counting was carried by an observer blind to treatment and viral group and at least 65 mCerulean+ neurons were counted per animal. ImageJ software was used to determine whether mCerulean+ neurons contained marker labeling with fluorescence intensity values $\times 2$ greater than background that was defined by the average fluorescence intensity value of 10 reference cells without marker labeling. Fluorescence intensity values in each mCerulean+ neuron, not corrected for background, was also analyzed. 
a ITR

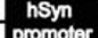

,

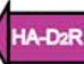
HA-D2R P
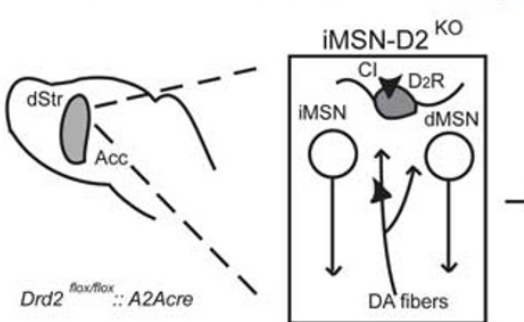

$\rightarrow$

b

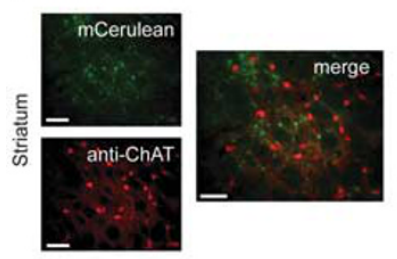

c

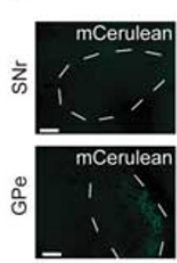

d
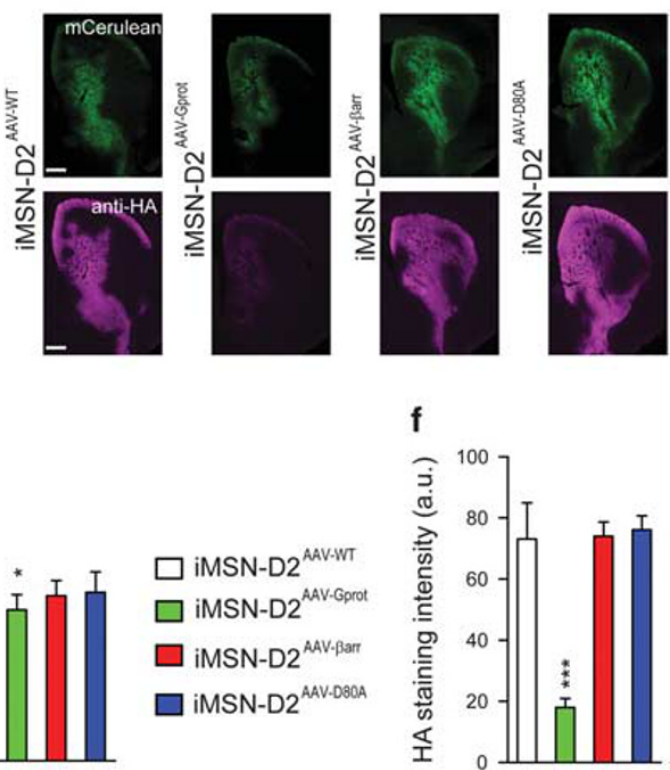

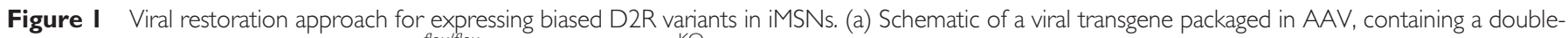

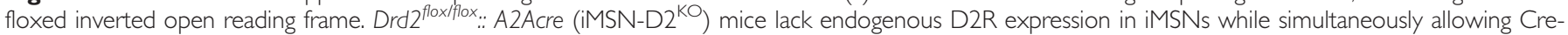

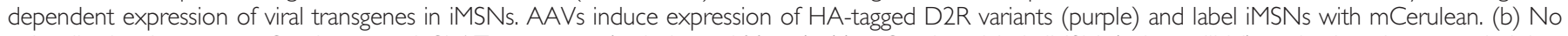

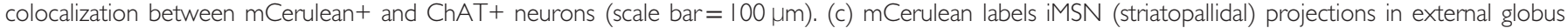

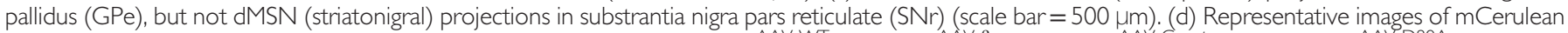

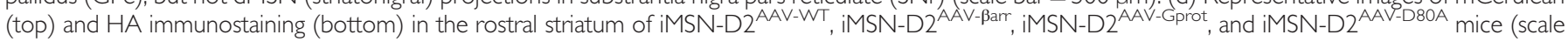

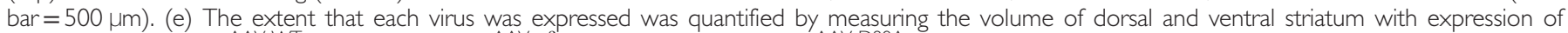

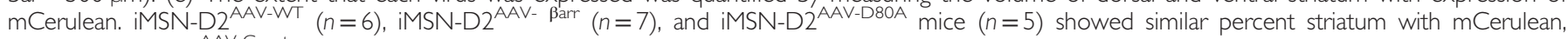

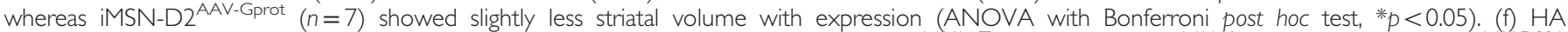

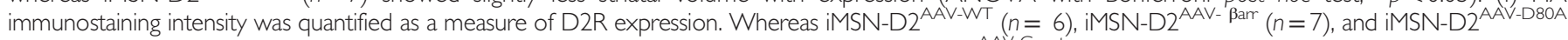

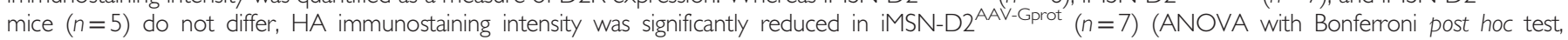
***** $p<0.001)$. Values represent mean \pm SEM.

\section{Locomotor Activity}

Open-field activity was measured in an Accuscan activity monitor (Omnitech Electronics, Columbus, $\mathrm{OH}$ ) and performed as previously described (Urs et al, 2012). Briefly, unstimulated open field locomotor activity was measured in $20 \mathrm{~min}$ increments over $60 \mathrm{~min}$ in drug-naive mice. For drug challenges, after 30 min of acclimation, drugs were injected, and mice returned to the open field. Locomotor activity was measured in $5 \mathrm{~min}$ intervals over $120 \mathrm{~min}$.

\section{Nestlet Shredding}

Nestlet shredding was performed as previously described (Li et al, 2006). Briefly, mice were placed in a clean cage with a preweighed $4 \mathrm{~cm} \times 4 \mathrm{~cm}$ cotton nestlet $(\sim 2 \mathrm{~g})$. After $3 \mathrm{~h}$, the amount of shredded nestlet was determined by weighing the remaining nestlet.

\section{Statistical Analyses}

Data were analyzed by standard one and two-way ANOVA and repeated-measures ANOVA tests; individual genotypes and viral groups were compared using post hoc Bonferroni's test in Graphpad Prism software (La Jolla, CA). Principal components analysis (PCA) was performed using JMP software (SAS, Cary, NC).

\section{RESULTS}

\section{Viral Restoration Strategy}

In order to impartially evaluate the functional consequences of biased D2R signaling in iMSNs, we used a viral restoration approach with biased D2R variants. First, mice carrying the conditional Drd2 allele (Drd2 flox/flox $)$ were crossed with BAC transgenic Adora2A-Cre ${ }^{+/-}$mice to create mice lacking D2Rs in iMSN (iMSN-D2 ${ }^{\mathrm{KO}}$ mice), while preserving D2R expression in all other cell types. Next, bilateral stereotactical injections of the AAV vectors into the dorsal (caudateputamen) and ventral striatum (nucleus accumbens) drove expression of a vector containing a human synapsin-1 promotor-driven double-floxed inverted ORF (DIO), the GFP variant mCerulean, a self-cleaving P2A sequence, and one of four HA-tagged mouse D2R variants in iMSNs (Figure 1a). The four D2R variants were identical to those published by Peterson et al (2015), wild-type ( $\left.{ }^{[\mathrm{WT}]} \mathrm{D} 2 \mathrm{R}\right)$, a $\beta$ arrestin signaling-biased variant ( ${ }^{[\mathrm{A} 135 \mathrm{R}, \mathrm{M} 140 \mathrm{D}]} \mathrm{D} 2 \mathrm{R}$; $\left.{ }^{[\beta a r r]} \mathrm{D} 2 \mathrm{R}\right)$, a G-protein signaling-biased variant ([L125N, ${ }^{\mathrm{Y} 133 \mathrm{~L}]} \mathrm{D} 2 \mathrm{R}$; $\left.{ }^{[\mathrm{Gprot}]} \mathrm{D} 2 \mathrm{R}\right)$, and a signaling-deficient point mutant $\left({ }^{[\mathrm{D} 80 \mathrm{~A}]} \mathrm{D} 2 \mathrm{R}\right)$ for a negative control. The four groups of mice (iMSN-D2 $2^{\text {AAV-WT }}$, iMSN-D2 $2^{\text {AAV-Gprot, }}$ iMSN$\mathrm{D} 2^{\mathrm{AAV}-\beta \text { arr }}$, and $\mathrm{iMSN}-\mathrm{D} 2^{\mathrm{AAV}-\mathrm{D} 80 \mathrm{~A}}$ ) differed only in the D2R variant their iMSNs express, and did not express endogenous iMSN-D2Rs. 
To verify exclusivity of expression in iMSNs, we examined mCerulean+ cells in striatal tissue sections that were immunostained with choline acetyl transferase (ChAT), a marker for cholinergic interneurons (Kharkwal et al, 2016a). We observed no colocalization between ChAT+ and mCerelean+ cells (Figure 1b; $n=25$ ChAT+, $n=138$ mCerulean+ neurons counted). iMSNs project to external globus pallidus (GPe), whereas direct pathway MSNs that express D1Rs (dMSNs) project to substrantia nigra reticulate (SNr) (Alexander et al, 1986). Exploiting this projection pattern, we looked for mCerulean+ axonal fibers in these two nuclei. As expected, mCerulean+ axonal fibers were observed in GPe, but not SNr, illustrating the specificity of transgene expression to the iMSN subtype (Figure 1c). Taken together, these data confirm viral expression was specific to iMSNs.

Next, we sought to quantify D2R expression in each of the iMSN-D2R ${ }^{A A V}$ groups. When expressed in HEK293T cells or overexpressed in iMSNs, the functionally selective variants show differences in membrane expression, and thus differences in D2R expression were expected in the iMSN$\mathrm{D} 2 \mathrm{R}^{\mathrm{AAV}}$ groups. However, changes in expression levels do not appear to significantly affect the pharmacological fidelity (trafficking, ligand binding, signal transduction) of the receptor variants in HEK293T cells (Peterson et al, 2015). We measured receptor expression in each of the iMSN$\mathrm{D} 2 \mathrm{R}^{\mathrm{AAV}}$ groups by immunostaining for the N-terminal HA tag on each receptor variant (Figure 1d). iMSN-D2 ${ }^{\text {AAV-WT }}$, iMSN-D2 $2^{\text {AAV- } \beta \text { arr }}$, and iMSN-D2AAV-D80A mice had similar expression of mCerulean and HA immunostaining intensity (Figure 1e and $\mathrm{f}$ ), with robust expression in rostral dorsomedial and ventromedial striatum (including nucleus accumbens) targeted by the stereotaxic coordinates (Figure 1d). Interestingly, iMSN-D2 ${ }^{\mathrm{AAV}-G \text { prot }}$ mice showed significantly less expression of mCerulean $\left(\mathrm{F}_{3,21}=3.30\right.$, $p<0.05$; Figure 1e) and HA immunostaining intensity $\left(\mathrm{F}_{3,21}=19.6, p<0.001\right.$; Figure 1f). Comparatively lower expression of the ${ }^{[\mathrm{Gprot}]} \mathrm{D} 2 \mathrm{R}$ mutant was also seen in the overexpression model (Peterson et al, 2015), and likely reflects compensatory downregulation of $\mathrm{D} 2 \mathrm{R}$ in the absence of $\beta$-arrestin-mediated desensitization of signaling. These differences in D2R expression present a significant caveat for the interpretation of our data, though we did not observe an association between behavior and expression level (Supplementary Figure S1), arguing that D2R expression level, once above a certain threshold, is not the primary factor for dopamine-driven functions. Furthermore, we wanted to avoid manipulating ${ }^{[\mathrm{Gprot}]} \mathrm{D} 2 \mathrm{R}$ levels because compensatory downregulation may be a way for the cell to avoid toxic levels of signaling. Thus, the iMSN-D2 $\mathrm{R}^{\mathrm{AAV}}$ groups display different, but expected, levels of expression.

\section{D2R Antagonist-Induced Signaling Is Mostly Mediated by D2R/G-Protein Blockade}

To impartially investigate D2R signaling in the iMSN$\mathrm{D} 2 \mathrm{R}^{\mathrm{AAV}}$ groups, we examined the expression of five cellular response markers following systemic haloperidol administration: c-fos, phospho-Ser-235/236 ribosomal protein S6 (pS6), phospho-Ser-10 histone H3 (pH3), early growth response-1 (egr-1), and Jun proto-oncogene (c-Jun). These markers are well-established responses to the D2R antagonist haloperidol (Rogue and Vincendon, 1992; Bertran-Gonzalez et al, 2008; Valjent et al, 2011; Kharkwal et al, 2016a), though each of these markers is downstream of different combinations of signaling pathways (Sheng and Greenberg, 1990; Bertran-Gonzalez et al, 2009; Bonito-Oliva et al, 2013; Bahrami and Drablos, 2016). Thus, we hypothesized that as $\mathrm{D} 2 \mathrm{R} / \mathrm{G}$-protein and $\mathrm{D} 2 \mathrm{R} / \beta$-arrestin signaling activate distinct signaling pathways, distinct combinations of cellular response markers in iMSN-D2R ${ }^{\mathrm{AAV}}$ groups might be present following haloperidol. We treated the four iMSN-D2 $2^{\text {AAV }}$ groups with vehicle, $0.5 \mathrm{mg} / \mathrm{kg}$, or $2 \mathrm{mg} / \mathrm{kg}$ haloperidol, harvested the brain $1 \mathrm{~h}$ later, and quantified responses in transfected iMSNs by counting colabeled mCerulean+ and cell response marker+ cells (Figure 2a-e). As a secondary quantification method we measured fluorescence intensity of the cell response markers in each cell counted (Supplementary Figure S2). As haloperidol could activate markers through off-target receptors, the inactive iMSND2 AAV-D80A group provided an important control. Thus, expression of a given marker was deemed statistically significant only when an active D2R variant was different from within-group saline treatment and haloperidol-treated iMSN-D2 ${ }^{\text {AAV-D80A }}$ mice. Haloperidol at $0.5 \mathrm{mg} / \mathrm{kg}$ caused a significant increase of $c$-fos in iMSN-D2 $2^{\mathrm{AAV}-\mathrm{WT}}$ mice (interaction, $\mathrm{F}_{6,42}=2.73, p<0.01$; Figure $2 \mathrm{a}$ ) and $\mathrm{pS} 6$ in iMSN-D2 ${ }^{\text {AAV-WT }}$ mice (interaction, $\mathrm{F}_{6,42}=2.99, p<0.01$; Figure $2 \mathrm{~b}$ ), but not in iMSN-D2 $2^{\text {AAV-Gprot }}$ or iMSN-D2 AAVBarr mice. Haloperidol at $0.5 \mathrm{mg} / \mathrm{kg}$ did not significantly alter $\mathrm{pH} 3$, egr-1, or c-Jun expression in any of the groups. Haloperidol at $2 \mathrm{mg} / \mathrm{kg}$ caused c-fos $(p<0.001)$, pS6 $(p<0.001)$, egr-1 (viral genotype, $\mathrm{F}_{3,42}=3.59, p<0.01$; Figure 2d), and c-Jun (interaction, $\mathrm{F}_{6,42}=6.48, p<0.001$; Figure 2e) but not pH3 expression in iMSN-D2 $2^{\mathrm{AAV}-\mathrm{WT}}$ mice. In iMSN-D2 $2^{\mathrm{AAV}-G \text { prot }}$ mice, $2 \mathrm{mg} / \mathrm{kg}$ haloperidol significantly increased $\mathrm{pH} 3$ (interaction, $\mathrm{F}_{6,42}=10.5, p<0.01$ ), pS6 $(p<0.01)$, egr-1 $(p<0.05)$, and c-Jun $(p<0.001)$ but not $\mathrm{c}$-fos. In iMSN-D2 $2^{\mathrm{AAV}-\beta \text { arr }}$ mice, only egr-1 $(p<0.05$; Figure $2 \mathrm{~d}$ ) was increased by $2 \mathrm{mg} / \mathrm{kg}$ haloperidol. We further analyzed responses to $2 \mathrm{mg} / \mathrm{kg}$ haloperidol with PCA. Each signaling response was treated as a unique feature of each animal and the first two principal components (PCs) were plotted (Figure 3). PC1 distinguished iMSN-D2 $2^{\mathrm{AAV}-\beta \text { arr }}$ from

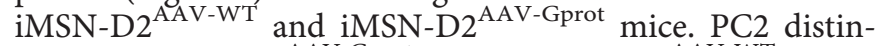
guished iMSN-D2 $2^{\text {AAV-Gprot }}$ from iMSN-D2 AAV-WT mice, although less robustly. Thus, between the two functionally selective variants, iMSN-D2 ${ }^{\mathrm{AAV}-G \text { prot }}$ mice most resemble iMSN-D2 $2^{\mathrm{AAV}-\mathrm{WT}}$ in their signaling response to haloperidol. The egr- 1 response, though, shows that the $\beta$-arrestin-biased variant (iMSN-D2 $2^{\text {AAV- } \beta \text { arr }}$ ) is capable of transducing a specific aspect of haloperidol-induced changes.

\section{Basic iMSN-D2R-Driven Behaviors Involve Both D2R/G- Protein and D2R/ $\beta$-Arrestin Signaling}

In the classic 'go-no-go' model of the basal ganglia, dopamine neurotransmission through iMSN-D2Rs disinhibits basal ganglia circuits and facilitates motor output (Alexander et al, 1986). Although canonical models of D2R signaling indicate that motor output is driven by G-proteinmediated reduction in intracellular cAMP (Kebabian and Calne, 1979), a role for $\beta$-arrestin-mediated signaling has also emerged (Beaulieu et al, 2005; Urs et al, 2012). Here, we sought to objectively assess the role for both D2R/G-protein 


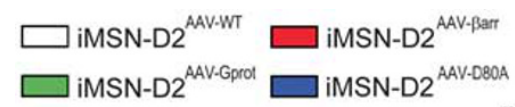

mCerulean / c-fos
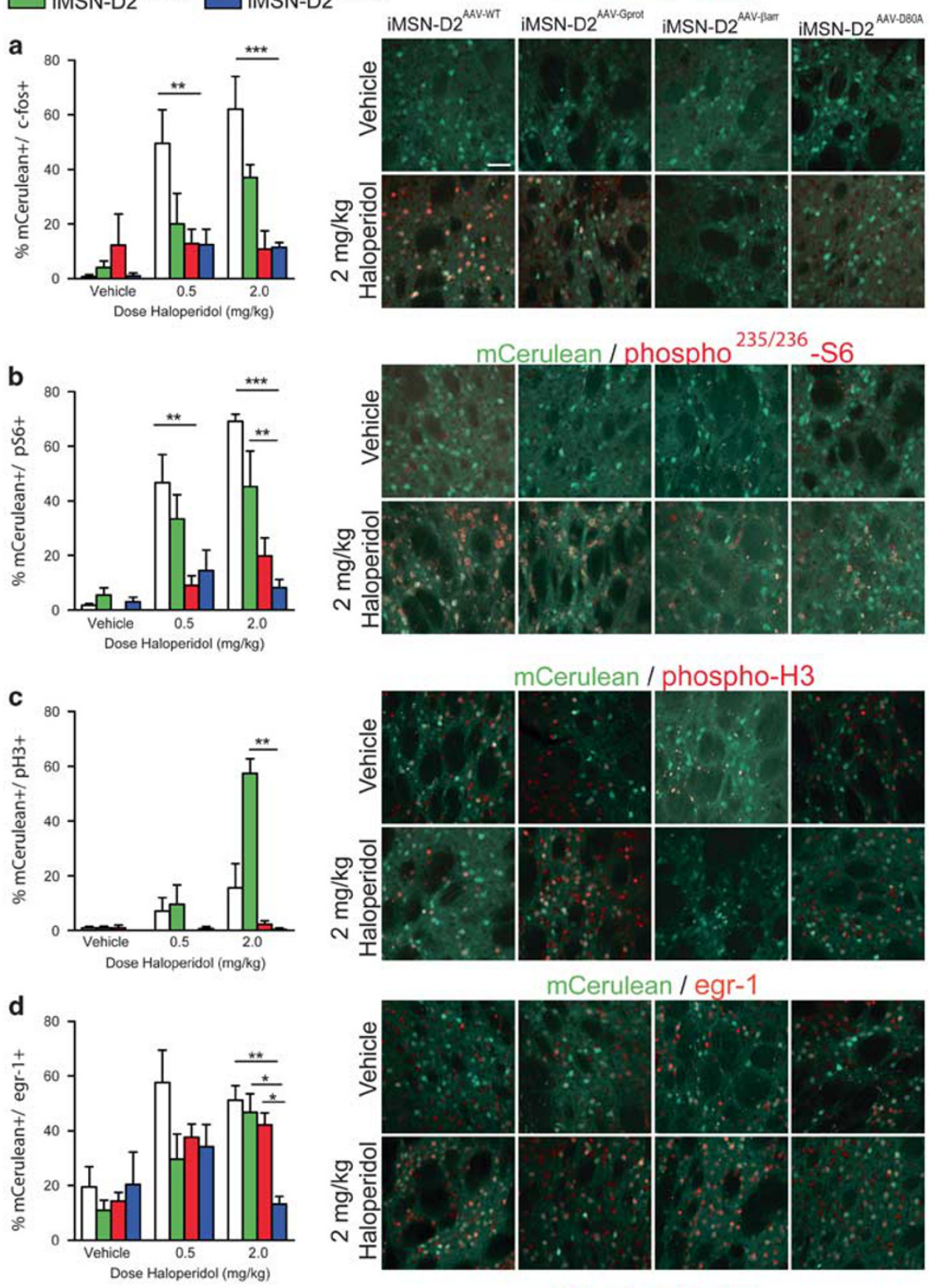

mCerulean / egr-1
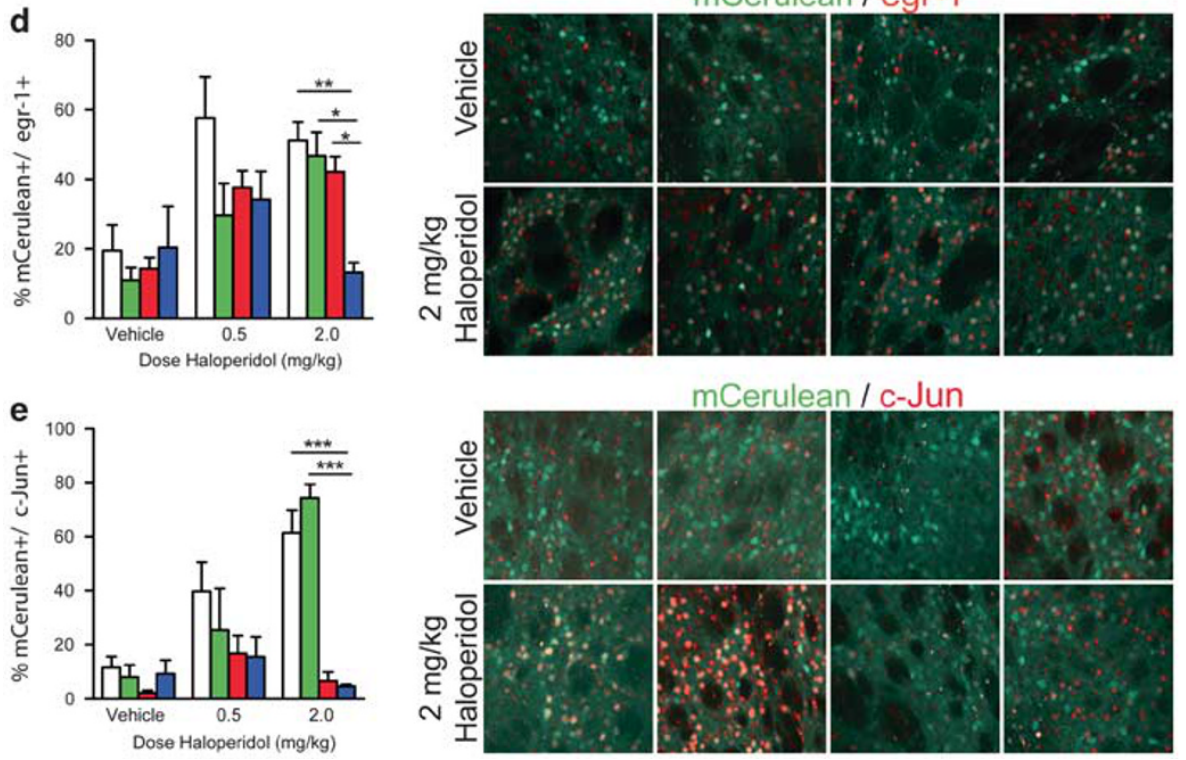

and $\mathrm{D} 2 \mathrm{R} / \beta$-arrestin signaling in stimulating motor output. We first examined deficits in iMSN-D $2^{\mathrm{KO}}$ before viral reconstitution to establish that motoric deficits were driven by a lack of iMSN-D2Rs. Indeed, iMSN-D $2^{\mathrm{KO}}$ mice showed a deficit in open-field behavior (interaction, $F_{2,28}=10.5$, $p<0.001$; Figure 4a), in agreement with others using the same Cre-lox strategy (Kharkwal et al, 2016b; Lemos et al, 2016). Next, we tested the iMSN-D2 ${ }^{\mathrm{AAV}}$ groups for 
Figure 2 D2R antagonist-induced signaling is mostly mediated by D2R/G-protein interaction. The five commonly used cellular response markers were assessed I h following i.p. injection of $0.5 \mathrm{mg} / \mathrm{kg}$ haloperidol $\left(n=6\right.$ iMSN-D2 ${ }^{\text {AAV-WT }}, n=5$ iMSN-D2 ${ }^{\text {AAV-Gprot }}, n=5$ iMSN-D2 ${ }^{\text {AAV-parr }}$, and $n=4$ iMSN-

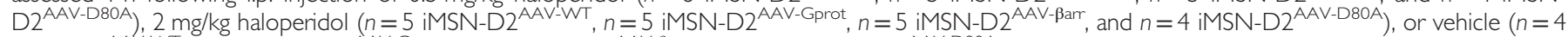
iMSN-D2 ${ }^{A A V-W T}, n=5$ iMSN-D2 ${ }^{A A V-G p r o t}, n=3$ iMSN-D2 $2^{A A V-\beta a r r}$, and $n=3$ iMSN-D2 ${ }^{\text {AAV-D } 80 A}$ ). mCerulean+ iMSNs in the dorsal striatum that were immunopositive for the cellular response marker were counted and are expressed as a percentage of total mCerulean+ iMSNs. Activation was defined as a significant increase over iMSN-D2 ${ }^{A A V-D 80 A}$ mice. Representative images of vehicle and $2 \mathrm{mg} / \mathrm{kg}$ haloperidol conditions are shown (scale bar = 50 um). (a) The $0.5 \mathrm{mg} / \mathrm{kg}$ haloperidol caused c-fos expression in iMSN-D2 ${ }^{\mathrm{AAV}-W T}$ mice (two-way ANOVA of viral genotype $\times$ drug dose interaction with Bonferroni post hoc

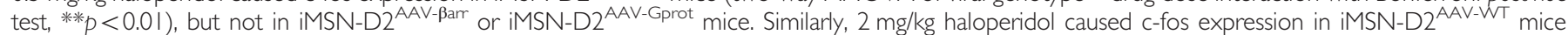

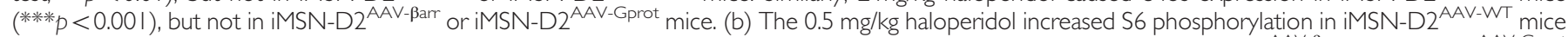
(two-way ANOVA of viral genotype $\times$ drug dose interaction with Bonferroni post hoc test, $* *$ * $<<0.0 \mathrm{I}$ ), but not in iMSN-D2 ${ }^{\text {AAV-Barr }}$ or iMSN-D2 ${ }^{\text {AAV-Gprot }}$

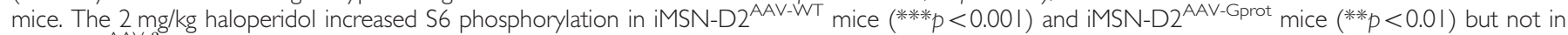
iMSN-D2 ${ }^{\text {AAV-parr }}$ mice. (c) The $0.5 \mathrm{mg} / \mathrm{kg}$ haloperidol did not increase $\mathrm{H3}$ phosphorylation in any of the viral genotypes. Alternatively, $2 \mathrm{mg} / \mathrm{kg}$ haloperidol increased $\mathrm{H} 3$ phosphorylation in iMSN-D2 ${ }^{A A V}$-Gprot mice (two-way ANOVA of viral genotype $\times$ drug dose interaction with Bonferroni post hoc test,

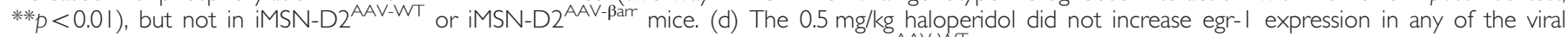
genotypes. The $2 \mathrm{mg} / \mathrm{kg}$ haloperidol, however, increased egr-I expression in iMSN-D2 ${ }^{A A V-W T}$ mice (two-way ANOVA on effect of viral genotype with

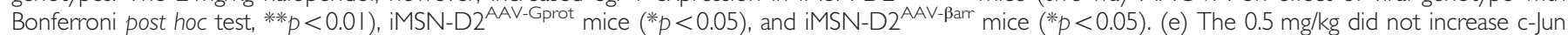
expression in any of the viral genotypes. The $2 \mathrm{mg} / \mathrm{kg}$ haloperidol induced c-Jun expression in iMSN-D2AAV-WT mice (two-way ANOVA on viral genotype $\times$ drug dose interaction with Bonferroni post hoc test, ${ }^{* * * *} p<0.00 \mathrm{I}$ ), and iMSN-D2 ${ }^{\text {AAV-Gprot }}(* * * *<<0.00 \mathrm{I})$. Values represent mean \pm SEM.

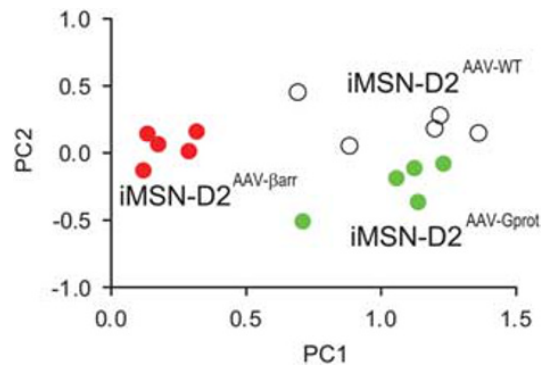

Figure 3 PCA in the cell activation markers over iMSN-D2 $2^{A A V-D 80 A}$ following $2 \mathrm{mg} / \mathrm{kg}$ haloperidol in iMSN-D2 ${ }^{\text {AAV-WT }}(n=5)$, iMSN-D2 ${ }^{\text {AAV- }}$ arr $(n=5)$, and iMSN-D2 $2^{A A V-G p r o t}$ mice $(n=5)$. PCI distinguishes the iMSND2 $2^{\text {AAV-Barr }}$ from iMSN-D2 $2^{A A V-W T}$ and IMSN-D2 ${ }^{\text {AAV-Gprot. }}$ PC2 distinguishes iMSN-D2 ${ }^{A A V-W T}$ from iMSN-D2 ${ }^{A A V-G p r o t}$. Points represent the signaling responses of individual animals. White $=i M S N-D 2^{A A V-W T}$, red $=i M S N-$ $\mathrm{D} 2^{\mathrm{AAV}-\text { Barr }}$, and green $=i M S N-D 2^{\mathrm{AAV}-\text { Gprot }}$ mice.

open-field locomotion. Whereas iMSN-D2 ${ }^{\mathrm{AAV}-\mathrm{WT}}$ restored open-field locomotion (time, $\mathrm{F}_{2,78}=6.22, \quad p<0.05$; Figure $4 \mathrm{~b})$, showing a significant difference from iMSND2 $2^{\mathrm{AAV}-\mathrm{D} 80 \mathrm{~A}}$ mice, both iMSN-D2 ${ }^{\mathrm{AAV}-\beta \text { arr }}$ and iMSN-D2 ${ }^{\mathrm{AAV}-}$ Gprot mice showed partial restoration of locomotion, with responses between iMSN-D2 ${ }^{\mathrm{AAV}-\mathrm{D} 80 \mathrm{~A}}$ and iMSN-D2 $2^{\mathrm{AAV}-\mathrm{WT}}$ mice. These differences could not be explained by differences in $\mathrm{D} 2 \mathrm{R}$ expression, as we observed no significant association between locomotion and HA intensity (Supplementary Figure S1). iMSN-D2 ${ }^{\mathrm{KO}}$ also showed a deficit in rearing behavior $(p<0.01$, Figure $4 \mathrm{c})$. iMSN-D2 ${ }^{\mathrm{AAV}-\mathrm{WT}}$ showed a trend $\left(\mathrm{F}_{2,28}=2.47, p=0.06\right)$ toward restoring rearing, though similar to open-field locomotion, neither iMSN$\mathrm{D} 2^{\mathrm{AAV}-\beta \text { arr }}$ nor iMSN-D2 ${ }^{\mathrm{AAV}-\mathrm{Gprot}}$ fully restored rearing (Figure 4d). Like the cellular c-fos response, neither D2R/ G-protein nor D2R/ $\beta$-arrestin signaling, alone, was sufficient to fully restore locomotion and rearing behavior.

Next, we examined nestlet shredding behavior, a natural rodent behavior that requires coordinated motor skills and is triggered by anxiogenic stimuli (Li et al, 2006; Angoa-Perez et al, 2013). We hypothesized that iMSN-D2Rs were required for nestlet shredding as they are involved in emotional valence and coordinated motor activity (Baik et al, 1995; Richard and Berridge, 2011). Indeed, iMSN-D2 ${ }^{\mathrm{KO}}$ were deficient in nestlet shredding behavior $(p<0.01$; Figure $4 \mathrm{e})$. Interestingly, iMSN-D2 $2^{\mathrm{AAV}-\text { Gprot }}$ mice $\left(\mathrm{F}_{3,49}=3.4, p<0.05\right)$, but not the other two active D2R variants, showed significant restoration of this behavior over iMSN-D2 $2^{\text {AAV-D } 80 A}$ mice. Thus, this particular behavior seems to be driven by D2R/Gprotein signaling. It is interesting to note that despite the fact that ${ }^{[\mathrm{Gprot}]} \mathrm{D} 2 \mathrm{R}$ had reduced receptor expression and incomplete locomotor activity, the nestlet shredding phenotype was completely restored. This, along with the sufficiency in haloperidol responses, indicates that ${ }^{[\mathrm{Gprot}]} \mathrm{D} 2 \mathrm{R}$ is fully functional at lower expression levels.

\section{$\beta$-Arrestin Signaling Drives the D2R Phencyclidine Response}

Along with basic, exploratory locomotion, dopamine signaling also mediates the psychomotor effect of drugs like amphetamine, cocaine, and phencyclidine (PCP) (Wise and Bozarth, 1987). Although each drug increases presynaptic dopamine release and locomotion, the precise mechanisms differ from drug to drug (Carboni et al, 1989; French et al, 1993; Covey et al, 2013; Daberkow et al, 2013). How these differing mechanisms affect D2R activation and whether biased signaling plays any role in distinguishing one drug response from another is not known. To investigate these questions, we tested the locomotor response to amphetamine, cocaine, and PCP in iMSN-D2 ${ }^{\mathrm{KO}}$ mice and iMSN-D2 $2^{\mathrm{AAV}}$ groups. We observed deficient responses to $3 \mathrm{mg} / \mathrm{kg}$ amphetamine (interaction, $F_{29,406}=26.5, p<0.001$; Figure 5a), $10 \mathrm{mg} / \mathrm{kg}$ cocaine (interaction, $\mathrm{F}_{29,406}=11.7, \quad p<0.001$; Figure $5 \mathrm{c}$ ), and $6 \mathrm{mg} / \mathrm{kg} \mathrm{PCP}$ in iMSN-D2 ${ }^{\mathrm{KO}}$ mice (interaction, $\mathrm{F}_{87,696}=6.72, p<0.01$; Figure $5 \mathrm{e}$ ), verifying previously published results (Dobbs et al, 2016; Urs et al, 2016). iMSN$\mathrm{D} 2^{\mathrm{AAV}-\mathrm{WT}}$ mice showed restoration of amphetamine-induced locomotion (interaction, $\mathrm{F}_{87,1131}=2.80, p<0.01$ where indicated; Figure 5b). iMSN-D2 ${ }^{\mathrm{AAV}-\beta \text { arr }}$ and iMSN-D2 ${ }^{\mathrm{AAV}-\text { Gprot }}$ mice demonstrated only partial restoration of amphetamineinduced locomotion (Figure 5b). With cocaine, however, iMSN-D2 ${ }^{\mathrm{AAV}-\mathrm{WT}}$ (interaction, $\mathrm{F}_{87,696}=6.75, p<0.001$ ), iMSN-D2 ${ }^{\text {AAV- } \beta \text { arr }}(p<0.001)$, and iMSN-D2 ${ }^{\text {AAV-Gprot mice }}$ $(p<0.01)$ all showed significant restoration of locomotion (Figure 5d). Cocaine-induced locomotion in iMSN-D2 ${ }^{\text {AAV-WT }}$ required D2R expression in both dorsal and ventral striatum, 


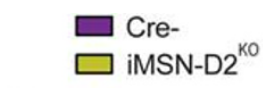

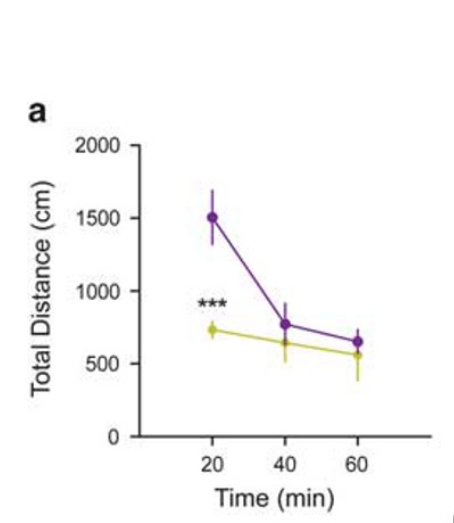

C
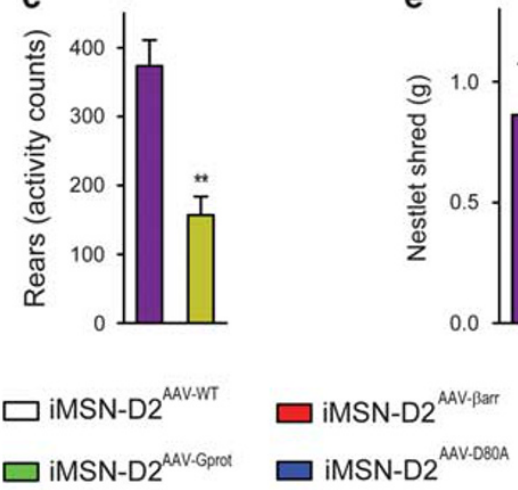

b

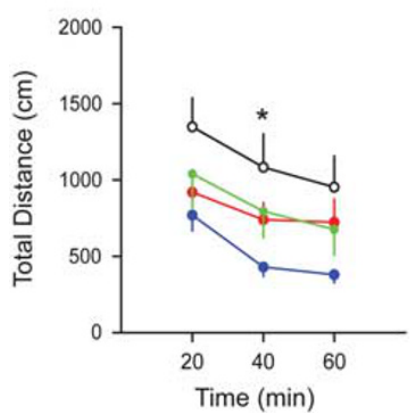

d

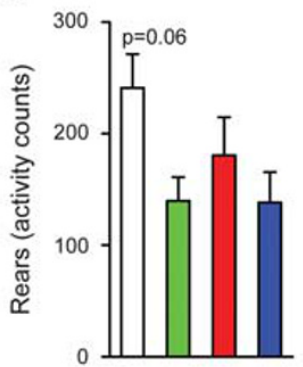

e

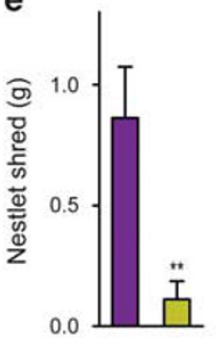

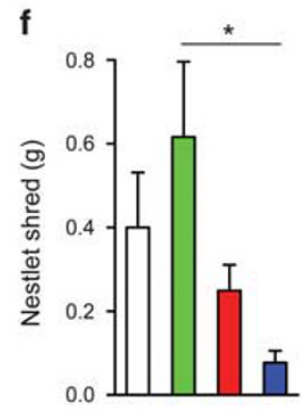

Figure 4 Examination of iMSN-D2R-biased signaling pathways in basic D2R-driven behaviors. (a) iMSN-D2 ${ }^{\mathrm{KO}}$ and Cre- littermate controls were tested in a novel open field for I h $\left(n=8 /\right.$ genotype). Locomotion was significantly reduced in iMSN-D2 ${ }^{\mathrm{KO}}$ (two-way repeated-measures ANOVA of genotype $\times$ time interaction with Bonferroni post hoc test, $\left.{ }^{*} * * *<<0.00 I\right)$. (b) Next, iMSN-D2 ${ }^{A A V-W T}(n=10)$, iMSN-D2 ${ }^{\text {AAV-Gprot }}(n=12)$, iMSN-D2 ${ }^{A A V-\beta a r r}(n=12)$, and iMSN-D2 ${ }^{\text {AAV-D80A }}(n=9)$ were tested in the novel open field. iMSN-D2 ${ }^{A A V-W T}$ showed restoration of open-field locomotion compared with iMSN-D2 ${ }^{\text {AAV-D80A }}$ (two-way repeated-measures ANOVA on effect of time with Bonferroni post hoc test, $\left.{ }^{*} p<0.05\right)$. iMSN-D2 ${ }^{\text {AAV-Gprot }}$ and iMSN-D2 ${ }^{\text {AAV-Barr }}$ mice showed intermediate restoration effects, with no significant difference found between these viral genotypes and iMSN-D2 ${ }^{A A V-W T}$ or iMSN-D2 ${ }^{A A V-D 80 A}$ mice. (c) Rearing was assessed concurrently to locomotion. Rearing was significantly reduced in iMSN-D2 ${ }^{\mathrm{KO}}$ compared with Cre- littermates (Student's t-test, *** $<0.0 \mathrm{I}$ ). (d) Rearing showed nonsignificant trend toward restoration in iMSN-D2 ${ }^{A A V-W T}$ compared with iMSN-D2 ${ }^{A A V-D 80 A}$ mice (ANOVA with Bonferroni post hoc test $p=0.06$ ), but not in iMSN-D2 ${ }^{A A V-G p r o t}$ and iMSN-D2 ${ }^{\text {AAV-Barr }}$ mice. (e) Nestlet shredding behavior was assessed in iMSN-D2 ${ }^{\mathrm{KO}}$ and Cre- littermate controls. iMSN-D2 ${ }^{\mathrm{KO}}$ showed a reduction in this behavior (Student's $t$-test, $* * * 0.01$ ). ( $f$ ) Nestlet shredding was significantly restored in iMSN-D2 ${ }^{A A V}$-Gprot mice (ANOVA with Bonferroni post hoc test, $* p<0.05$ ). Values represent mean $\pm \mathrm{SEM}$.

as expression of $\mathrm{D} 2 \mathrm{R}$ individually in these subregions was insufficient in restoring locomotion (Supplementary Figure S3). Intriguingly, PCP-induced locomotion was potentiated in iMSN-D2 ${ }^{\mathrm{AAV}-\beta a r r}$ (interaction, $\mathrm{F}_{87,696}=6.72$, $p<0.01)$, whereas iMSN-D2 ${ }^{\mathrm{AAV}-\mathrm{Gprot}}$ showed minimal restoration (Figure $5 \mathrm{f}$ ). These findings illustrate selective roles for $\mathrm{D} 2 \mathrm{R} / \mathrm{G}$-protein and $\mathrm{D} 2 \mathrm{R} / \beta$-arrestin signaling in the locomotor response to these three drugs, with a surprisingly robust role for $\mathrm{D} 2 \mathrm{R} / \beta$-arrestin signaling in $\mathrm{PCP}$-induced locomotion. Interestingly, iMSN-D ${ }^{\mathrm{KO}}$ mice showed normal conditioned place preference for cocaine, illustrating the specificity of the iMSN-D2 ${ }^{\mathrm{KO}}$ effect to acute psychomotor effects, at least for cocaine (Supplementary Figure S4).

\section{DISCUSSION}

D2Rs are critical for many normal neurobehavioral functions and are a target of therapeutics for Parkinson's disease, schizophrenia, and other basal ganglia-related disorders.
Since the discovery of $\beta$-arrestin-mediated D2R signaling, a growing body of literature has demonstrated biased D2R signaling and its importance in various contexts (Beaulieu et al, 2005; Masri et al, 2008; Allen et al, 2011; Urs et al, 2015; Urs et al, 2016). Few of these studies, however, have examined biased D2R signaling in a manner that does not disrupt pleiotropic signaling proteins. Using biased receptor viral reconstitution, we examined the functional consequences of biased D2R signaling in a way that preserves nondopaminergic signaling and limits our manipulations to iMSNs. We show that cellular responses to D2R antagonism are mostly driven by D2R/G-protein signaling, though D2R/ $\beta$-arrestin signaling contributes as well. Behaviorally, we show that neither D2R/G-protein nor D2R/ $\beta$-arrestin signaling, alone, can drive locomotion. Finally, we show that $\mathrm{D} 2 \mathrm{R} / \beta$-arrestin signaling potentiates phencyclidine-induced psychomotor effects. These data highlight the importance of iMSN-D2Rs for neurobehavioral functions and demonstrate GPCR functional selectivity with unprecedented precision. 

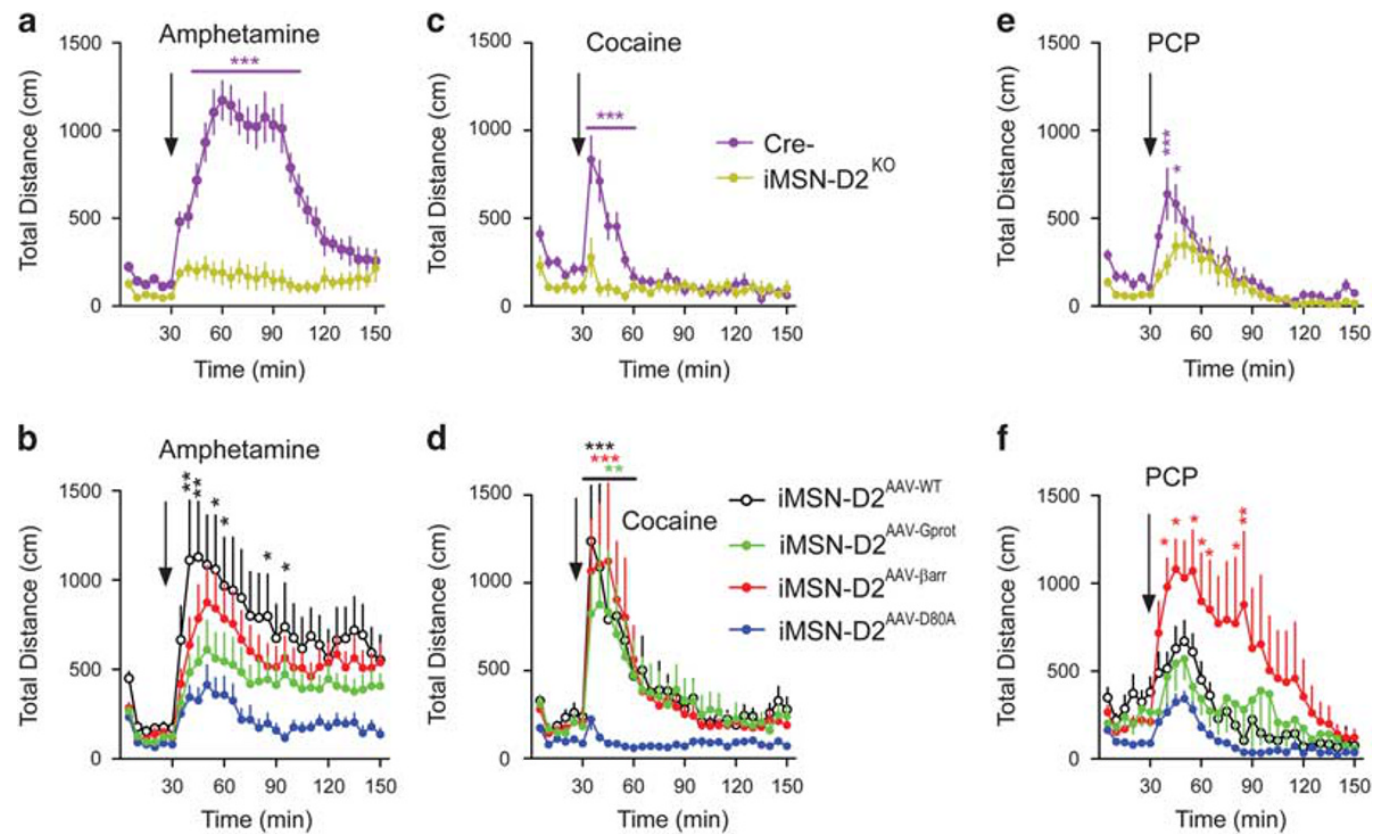

Figure 5 Examination of iMSN-D2R-biased signaling pathways in psychomotor drug effects. (a) iMSN-D2 ${ }^{\mathrm{KO}}(n=8)$ and Cre- $(n=8)$ littermate controls were tested for their locomotor response to $3 \mathrm{mg} / \mathrm{kg}$ amphetamine. Amphetamine-induced locomotion was significantly reduced in iMSN-D2 ${ }^{\mathrm{KO}}$ mice following $3 \mathrm{mg} / \mathrm{kg}$ compared with Cre-controls (two-way repeated-measures ANOVA on genotype $\times$ time interaction with Bonferroni post hoc tests within time points, ${ }^{*} * * * 0.001$ ). (b) Next, iMSN-D2 ${ }^{A A V-W T}(n=10)$, iMSN-D2 ${ }^{A A V-G p r o t}(n=12)$, iMSN-D2 ${ }^{A A V-\beta a r r}(n=12)$, and iMSN-D2 ${ }^{A A V-D 80 A}(n=9)$ were tested for amphetamine-induced locomotion. IMSN-D2 ${ }^{A A V-W T}$ mice showed significant restoration of amphetamine-induced locomotion over iMSN-D2 ${ }^{A A V}$ D80A (two-way repeated-measures ANOVA on viral genotype $\times$ time interaction with Bonferroni post hoc tests, * $p<0.05$ and $* *$ * $p<0.0$ I). iMSN-D2 ${ }^{\text {AAV-Gprot }}$ and IMSN-D2 ${ }^{\text {AAV-Barr }}$ mice showed intermediate restoration effects, with no significant difference found between these viral genotypes and iMSN-D2 ${ }^{\text {AAV-WT }}$ or iMSN-D2 ${ }^{\text {AAV-D80A }}$ mice. (c) Locomotion was significantly reduced in iMSN-D2 ${ }^{\mathrm{KO}}$ following $10 \mathrm{mg} / \mathrm{kg}$ cocaine (two-way RMANOVA on genotype $\times$ time interaction with Bonferroni post hoc tests, $\left.{ }^{*} * * *=0.00 I\right)$. (d) iMSN-D2 ${ }^{A A V-W T}(n=6)$, iMSN-D2 ${ }^{A A V-G p r o t}(n=8)$, iMSN-D2 $2^{A A V-\beta a r r}(n=8)$, and iMSN-D2 ${ }^{A A V}$ -

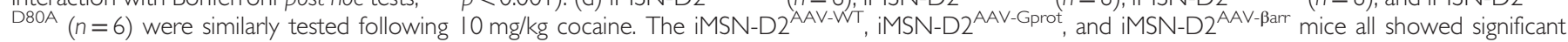
restoration of cocaine induced locomotion (two-way repeated-measures ANOVA on genotype $\times$ time interaction with Bonferroni post hoc tests, $* * * 20.0$ I and *** $^{*}<<0.00 \mathrm{I}$ ). (e) Finally, PCP-induced locomotion was tested in iMSN-D2 ${ }^{\mathrm{KO}}$ and Cre- mice that was significantly reduced in iMSN-D2 ${ }^{\mathrm{KO}}$ mice (two-way repeated-measures ANOVA on genotype $\times$ time interaction with Bonferroni post hoc tests, $* p<0.05$ and $* * p<0.00 \mathrm{I})$. (f) iMSN-D2 ${ }^{\text {AAV-parr }}$ mice $(n=8)$ showed significant restoration of PCP-induced locomotion over iMSN-D2 ${ }^{A A V-D 80 A}$ mice $(n=6)$ (two-way repeated-measures ANOVA on genotype $\times$ time interaction with Bonferroni post hoc tests, ${ }^{*} p<0.05$ and ${ }^{*}$ * $p<0.0$ I Bonferroni post hoc tests). iMSN-D2 ${ }^{A A V-W T}(n=6)$ and iMSN-D2 ${ }^{\text {AAV-Gprot }}$ mice $(n=8)$, however, only showed intermediate restoration, not significantly differing from iMSN-D2 ${ }^{A A V-D 80 A}$ mice. Values represent mean \pm SEM.

\section{G-Protein-Biased Haloperidol Responses}

Our finding that most of the cell signaling response to haloperidol is driven by blockade of acute D2R/G-protein signaling is in concert with existing data. Several studies have illustrated the importance of adenylyl cyclase-cAMP-PKADARPP32 signaling for haloperidol-induced phosphorylation of $\mathrm{S} 6$ and $\mathrm{H} 3$, and the expression of c-fos and egr-1 (Bertran-Gonzalez et al, 2008; Bertran-Gonzalez et al, 2009; Valjent et al, 2011; Bonito-Oliva et al, 2013). On the other hand, ERK $1 / 2$, which is activated by both D2R/G-protein and $\mathrm{D} 2 \mathrm{R} / \beta$-arrestin signaling (Peterson et al, 2015), is critical for haloperidol-induced signaling as well (Bertran-Gonzalez et al, 2008; Valjent et al, 2011). Our approach confirms that the metabolic changes induced by haloperidol are mostly due to D2R/G-protein signaling disruption. These data are in support of a model where antipsychotics mediate gene transcriptional changes and long-term effects through antagonism of D2R/G-protein signaling (Bateup et al, 2010; Allen et al, 2011), whereas antagonism of $\mathrm{D} 2 \mathrm{R} / \beta$-arrestin signaling mediates nontranscriptional changes to cell physiology that mediate the reduction in the positive symptoms of schizophrenia (Masri et al, 2008; Allen et al, 2011; Urs et al, 2012). An important update to this model is our finding that antagonism of $\mathrm{D} 2 \mathrm{R} / \beta$-arrestin signaling is capable of driving haloperidol-induced egr-1 expression. Thus, some overlap of D2R/G-protein and D2R/ $\beta$-arrestin signaling likely occurs. Furthermore, the inability of iMSN-D2R ${ }^{\mathrm{AAV}-\text { Gprot }}$ mice to reconstitute c-fos expression points to the necessity for cooperation between D2R/G-protein and D2R/ $\beta$-arrestin signaling for certain neuronal changes. As it is becoming understood that iMSNs are a genetically heterogeneous cell population (Gokce et al, 2016), the biased effects of haloperidol on unique subpopulations of iMSNs will be interesting to dissect in the future.

\section{A Range of Signaling Modes in D2R-Driven Behaviors}

Our finding that reconstitution of $\mathrm{D} 2 \mathrm{R} / \beta$-arrestin or D2R/Gprotein signaling only partially reconstitutes open-field locomotion, individually, are interesting in the context of Parkinson's disease. Recent studies using iMSN-D2R ${ }^{\mathrm{KO}}$ mice show that loss of D2Rs in iMSNs mimics parkinsonian hypokinesia by enhancing GABAergic transmission from iMSNs to GPe, and by enhancing iMSN lateral inhibition of dMSNs (Dobbs et al, 2016; Lemos et al, 2016). Our data point to a cooperative role for $\mathrm{D} 2 \mathrm{R} / \beta$-arrestin and $\mathrm{D} 2 \mathrm{R} / \mathrm{G}$-protein 
signaling in mediating these physiological effects and driving open-field locomotion. Future work could focus on determining how each signaling pathway contributes to the maintenance of normal iMSN physiology, though targeting one biased D2R signaling pathway is unlikely to be a 'silver bullet' for reversing parkinsonian symptoms. Our nestlet shredding data, however, illustrate that a single biased D2R signaling pathway is capable of driving a $\mathrm{D} 2 \mathrm{R}$-dependent behavior on its own.

Finally, we illustrated the complex role that biased D2R signaling plays in mediating psychotropic drug responses. Amphetamine, cocaine, and PCP require iMSN-D2Rs to mediate their acute effect on locomotion, making the viral reconstitution approach ideal for elucidating the biased D2R signaling mechanisms of these drugs. Despite a similar requirement of iMSN-D2Rs, amphetamine, cocaine, and PCP engage biased D2R signaling in different ways. Amphetamine, like unstimulated open-field locomotion, requires a combination of $\mathrm{D} 2 \mathrm{R} / \beta$-arrestin and $\mathrm{D} 2 \mathrm{R} / \mathrm{G}$ protein signaling as neither iMSN-D2 $\mathrm{R}^{\mathrm{AAV}-\mathrm{Gprot}}$ nor iMSN$\mathrm{D} 2 \mathrm{R}^{\mathrm{AAV}-\beta \mathrm{arr}}$ mice fully restore amphetamine-induced locomotion. On the other hand, iMSN-D2R AAV-Gprot and iMSN$\mathrm{D} 2 \mathrm{R}^{\mathrm{AAV}-\beta \text { arr }}$ both individually restored cocaine-induced locomotion. Both amphetamine and cocaine directly increase dopamine transmission. Amphetamine, though, is a socalled dopamine 'releaser', depleting vesicular stores and promoting nonexocytotic dopamine efflux via reverse transport, whereas cocaine merely inhibits the dopamine transporter (Sulzer, 2011). These differing pharmacologies translate to a difference in their effects on tonic dopamine signaling. Although both drugs enhance phasic dopamine signals, amphetamine also enhances tonic dopamine signaling by depleting the reserve pool of dopamine in the presynaptic terminal (Covey et al, 2013; Daberkow et al, 2013). Our results raise the intriguing possibility that biased $\mathrm{D} 2 \mathrm{R}$ signaling, at least in part, translates the difference between tonic and phasic dopamine signals. For instance, although the phasic dopamine signal elicited by cocaine stimulation may initiate a D2R signal that either $\mathrm{D} 2 \mathrm{R} / \beta$ arrestin or D2R/G-protein are capable of transducing, say the activation of ERK1/2 (Peterson et al, 2015), the amphetamine-induced increase in tonic dopamine signal may engage cooperative D2R/G-protein and D2R/ $\beta$-arrestin signaling that stimulates ERK $1 / 2$ and combinations of other signaling networks. Further work will be required to test these hypotheses, but these data lend support to different effects of cocaine and amphetamine on iMSN signaling and plasticity (Jedynak et al, 2016). Contrasting both cocaine and amphetamine-induced locomotion, PCP-induced locomotion is mostly driven by $\mathrm{D} 2 \mathrm{R} / \beta$-arrestin signaling. This difference may reflect the role of $\mathrm{D} 2 \mathrm{R} / \beta$-arrestin signaling in integrating glutamatergic and phasic dopamine signals elicited by PCP (French et al, 1993), and a case where the homeostatic balance between G-protein and $\beta$-arrestin signaling is shifted toward $\beta$-arrestin bias. Furthermore, as PCP-induced locomotion is a long-standing model of schizophrenic symptoms, these data support an approach that targets $\mathrm{D} 2 \mathrm{R} / \beta$-arrestin signaling for the treatment of schizophrenia (Allen et al, 2011; Urs et al, 2016). Finally, it is important to note that only single doses of these drugs were tested; full dose responses may reveal more nuance to the roles of these signaling pathways.

\section{CONCLUSIONS}

In summary, this study utilized a viral reconstitution approach for studying biased D2R signaling with cell typespecific resolution. The work here highlights the complexity of D2R signaling within iMSNs in the context of behavioral, pharmacological, and physiological functions. These findings have the potential to shape strategies focused on biased D2R pharmacotherapies for a range of brain disorders.

\section{FUNDING AND DISCLOSURE}

This work was supported in part by NIH grants R37MH073853, U19-MH082441 to MGC, and F31-DA041160 to TFP. MGC is an inventor on patents and patent applications pertaining to an adjunct 5-HTP SR method of treatment for treatment-resistant depression. MGC owns stock in Evecxia, a company aiming at developing a 5-HTP SR drug. MGC also owns stock in Acadia Pharmaceuticals and has received compensation in the form of honoraria for lecturing at various academic institutions. The other authors declare no conflict of interest.

\section{REFERENCES}

Alexander GE, DeLong MR, Strick PL (1986). Parallel organization of functionally segregated circuits linking basal ganglia and cortex. Annu Rev Neurosci 9: 357-381.

Allen JA, Yost JM, Setola V, Chen X, Sassano MF, Chen M et al (2011). Discovery of beta-arrestin-biased dopamine D2 ligands for probing signal transduction pathways essential for antipsychotic efficacy. Proc Natl Acad Sci USA 108: 18488-18493.

Angoa-Perez M, Kane MJ, Briggs DI, Francescutti DM, Kuhn DM (2013). Marble burying and nestlet shredding as tests of repetitive, compulsive-like behaviors in mice. J Vis Exp 82: 50978.

Bahrami S, Drablos F (2016). Gene regulation in the immediateearly response process. Adv Biol Regul 62: 37-49.

Baik JH, Picetti R, Saiardi A, Thiriet G, Dierich A, Depaulis A et al (1995). Parkinsonian-like locomotor impairment in mice lacking dopamine D2 receptors. Nature 377: 424-428.

Bateup HS, Santini E, Shen W, Birnbaum S, Valjent E, Surmeier DJ et al (2010). Distinct subclasses of medium spiny neurons differentially regulate striatal motor behaviors. Proc Natl Acad Sci USA 107: 14845-14850.

Beaulieu JM, Sotnikova TD, Marion S, Lefkowitz RJ, Gainetdinov RR, Caron MG (2005). An Akt/beta-arrestin 2/PP2A signaling complex mediates dopaminergic neurotransmission and behavior. Cell 122: 261-273.

Bello EP, Mateo Y, Gelman DM, Noain D, Shin JH, Low MJ et al (2011). Cocaine supersensitivity and enhanced motivation for reward in mice lacking dopamine D2 autoreceptors. Nat Neurosci 14: 1033-1038.

Bertran-Gonzalez J, Bosch C, Maroteaux M, Matamales M, Herve $\mathrm{D}$, Valjent $\mathrm{E}$ et al (2008). Opposing patterns of signaling activation in dopamine D1 and D2 receptor-expressing striatal neurons in response to cocaine and haloperidol. J Neurosci 28: 5671-5685.

Bertran-Gonzalez J, Hakansson K, Borgkvist A, Irinopoulou T, Brami-Cherrier K, Usiello A et al (2009). Histone H3 phosphorylation is under the opposite tonic control of dopamine D2 and adenosine A2A receptors in striatopallidal neurons. Neuropsychopharmacology 34: 1710-1720.

Bohn LM, Gainetdinov RR, Lin FT, Lefkowitz RJ, Caron MG (2000). $\mathrm{Mu}$-opioid receptor desensitization by beta-arrestin-2 determines morphine tolerance but not dependence. Nature 408: 720-723. 
Bonito-Oliva A, Pallottino S, Bertran-Gonzalez J, Girault JA, Valjent E, Fisone G (2013). Haloperidol promotes mTORC1-dependent phosphorylation of ribosomal protein S6 via dopamine- and cAMP-regulated phosphoprotein of $32 \mathrm{kDa}$ and inhibition of protein phosphatase-1. Neuropharmacology 72: 197-203.

Carboni E, Imperato A, Perezzani L, Di Chiara G (1989). Amphetamine, cocaine, phencyclidine and nomifensine increase extracellular dopamine concentrations preferentially in the nucleus accumbens of freely moving rats. Neuroscience 28: 653-661.

Carlsson A (1978). Antipsychotic drugs, neurotransmitters, and schizophrenia. Am J Psychiatry 135: 165-173.

Centonze D, Grande C, Usiello A, Gubellini P, Erbs E, Martin AB et al (2003). Receptor subtypes involved in the presynaptic and postsynaptic actions of dopamine on striatal interneurons. J Neurosci 23: 6245-6254.

Covey DP, Juliano SA, Garris PA (2013). Amphetamine elicits opposing actions on readily releasable and reserve pools for dopamine. PLoS ONE 8: e60763.

Daberkow DP, Brown HD, Bunner KD, Kraniotis SA, Doellman MA, Ragozzino ME et al (2013). Amphetamine paradoxically augments exocytotic dopamine release and phasic dopamine signals. J Neurosci 33: 452-463.

Dobbs LK, Kaplan AR, Lemos JC, Matsui A, Rubinstein M, Alvarez VA (2016). Dopamine regulation of lateral inhibition between striatal neurons gates the stimulant actions of cocaine. Neuron $\mathbf{9 0}$ : $1100-1113$.

French ED, Mura A, Wang T (1993). MK-801, phencyclidine (PCP), and PCP-like drugs increase burst firing in rat A10 dopamine neurons: comparison to competitive NMDA antagonists. Synapse 13: $108-116$.

Gerfen CR, Engber TM, Mahan LC, Susel Z, Chase TN, Monsma FJ et al (1990). D1 and D2 dopamine receptor regulated gene expression of striatonigral and striatopalidal neurons. Science 250: $1429-1432$.

Gokce O, Stanley G, Treutlein B, Neff NF, Camp GJ, Malenka RC et al (2016). Cellular taxonomy of the mouse striatum as revealed by single-cell RNA-Seq. Cell Rep 16: 1126-1137.

Jedynak J, Hearing M, Ingebretson A, Ebner SR, Kelly M, Fischer RA et al (2016). Cocaine and amphetamine induce overlapping but distinct patterns of AMPAR plasticity in nucleus accumbens medium spiny neurons. Neuropsychopharmacology 41: 464-476.

Kane J, Honigfeld G, Singer J, Meltzer H (1988). Clozapine for the treatment-resistant schizophrenic. A double-blind comparison with chlorpromazine. Arch Gen Psychiatry 45: 789-796.

Kebabian JW, Calne DB (1979). Multiple receptors for dopamine. Nature 277: 93-96.

Kharkwal G, Brami-Cherrier K, Lizardi-Ortiz JE, Nelson AB, Ramos M, Del Barrio D et al (2016a). Parkinsonism driven by antipsychotics originates from dopaminergic control of striatal cholinergic interneurons. Neuron 91: 67-78.

Kharkwal G, Radl D, Lewis R, Borrelli E (2016b). Dopamine D2 receptors in striatal output neurons enable the psychomotor effects of cocaine. Proc Natl Acad Sci USA 113: 11609-11614.

Lemos JC, Friend DM, Kaplan AR, Shin JH, Rubinstein M, Kravitz AV et al (2016). Enhanced GABA transmission drives bradykinesia following loss of dopamine D2 receptor signaling. Neuron 90: 824-838.

Li X, Morrow D, Witkin JM (2006). Decreases in nestlet shredding of mice by serotonin uptake inhibitors: comparison with marble burying. Life Sci 78: 1933-1939.
Lieberman JA, Stroup TS, McEvoy JP, Swartz MS, Rosenheck RA, Perkins DO et al (2005). Effectiveness of antipsychotic drugs in patients with chronic schizophrenia. New Engl J Med 353: 1209-1223.

Masri B, Salahpour A, Didriksen M, Ghisi V, Beaulieu JM, Gainetdinov $\mathrm{RR}$ et al (2008). Antagonism of dopamine D2 receptor/beta-arrestin 2 interaction is a common property of clinically effective antipsychotics. Proc Natl Acad Sci USA 105: 13656-13661.

Nishi A, Snyder GL, Greengard P (1997). Bidirectional regulation of DARPP-32 phosphorylation by dopamine. J Neurosci 17: 8147-8155.

Peterson SM, Pack TF, Wilkins AD, Urs NM, Urban DJ, Bass CE et al (2015). Elucidation of G-protein and beta-arrestin functional selectivity at the dopamine D2 receptor. Proc Natl Acad Sci USA 112: 7097-7102.

Richard JM, Berridge KC (2011). Nucleus accumbens dopamine/ glutamate interaction switches modes to generate desire versus dread: $\mathrm{D}(1)$ alone for appetitive eating but $\mathrm{D}(1)$ and $\mathrm{D}(2)$ together for fear. J Neurosci 31: 12866-12879.

Rogue P, Vincendon G (1992). Dopamine D2 receptor antagonists induce immediate early genes in the rat striatum. Brain Res Bull 29: 469-472.

Seeman P, Lee T, Chau-Wong M, Wong K (1976). Antipsychotic drug doses and neuroleptic/dopamine receptors. Nature 261: 717-719.

Sheng M, Greenberg ME (1990). The regulation and function of c-fos and other immediate early genes in the nervous system. Neuron 4: 477-485.

Sulzer D (2011). How addictive drugs disrupt presynaptic dopamine neurotransmission. Neuron 69: 628-649.

Urs NM, Bido S, Peterson SM, Daigle TL, Bass CE, Gainetdinov RR et al (2015). Targeting beta-arrestin2 in the treatment of L-DOPA-induced dyskinesia in Parkinson's disease. Proc Natl Acad Sci USA 112: E2517-E2526.

Urs NM, Gee SM, Pack TF, McCorvy JD, Evron T, Snyder JC et al (2016). Distinct cortical and striatal actions of a beta-arrestinbiased dopamine D2 receptor ligand reveal unique antipsychoticlike properties. Proc Natl Acad Sci USA 113: E8178-E8186.

Urs NM, Snyder JC, Jacobsen JP, Peterson SM, Caron MG (2012). Deletion of GSK3beta in D2R-expressing neurons reveals distinct roles for beta-arrestin signaling in antipsychotic and lithium action. Proc Natl Acad Sci USA 109: 20732-20737.

Valjent E, Bertran-Gonzalez J, Bowling H, Lopez S, Santini E, Matamales $M$ et al (2011). Haloperidol regulates the state of phosphorylation of ribosomal protein S6 via activation of PKA and phosphorylation of DARPP-32. Neuropsychopharmacology 36: 2561-2570.

Weinberger DR (1987). Implications of normal brain development for the pathogenesis of schizophrenia. Arch Gen Psychiatry 44: 660-669.

Weiner DM, Levey AI, Sunahara RK, Niznik HB, O'Dowd BF, Seeman $\mathrm{P}$ et al (1991). D1 and D2 dopamine receptor mRNA in rat brain. Proc Natl Acad Sci USA 88: 1859-1863.

Whalen EJ, Rajagopal S, Lefkowitz RJ (2011). Therapeutic potential of beta-arrestin- and G protein-biased agonists. Trends Mol Med 17: 126-139.

Wise RA, Bozarth MA (1987). A psychomotor stimulant theory of addiction. Psychol Rev 94: 469-492.

Xiao X, Li J, Samulski RJ (1998). Production of high-titer recombinant adeno-associated virus vectors in the absence of helper adenovirus. J Virol 72: 2224-2232.

Supplementary Information accompanies the paper on the Neuropsychopharmacology website (http://www.nature.com/npp) 